\title{
Power Management of Hybrid Micro-grid System by a Generic Centralized Supervisory Control Scheme
}

\author{
Mir Nahidul Ambia, Ahmed Al-Durra*, Cedric Caruana, and S. M. Muyeen \\ Electrical Engineering Department, The Petroleum Institute, P.O.Box 2533, Abu Dhabi, UAE \\ E-mail*: aaldurra@pi.ac.ae, contact no: +97126075511.
}

Abstract - This paper presents a generic centralized supervisory control scheme for the power management of multiple power converters based hybrid micro-grid system. The system consists of wind generators, photovoltaic system, multiple parallel connected power converters, utility grid, ac and dc loads. Power management of the micro-grid is performed under two cases: grid mode and local mode. Central supervisory unit (CSU) generates command signal to ensure the power management during the two modes. In local mode, the dc loads in the ac-dc hybrid system can be controlled. In the case of grid mode operation, power flow between the utility grid and micro-grid is controlled. A novel feature of this paper is the incorporation of the multiple power converters. The generated command signal from the CSU can also control the operation of the multiple power converters in both grid and local modes. An additional feature is the incorporation of sodium sulfur battery energy storage system (NAS BESS) which is used to smooth the output power fluctuation of the wind farm. The effectiveness of the control scheme is also verified using real time load pattern. The simulation is performed in PSCAD/EMTDC.

Key words - Central supervisory unit, micro-grid, NAS battery, power smoothing, power management, wind turbine.

\section{INTRODUCTION}

The ever increasing energy consumption and demand for electricity has taken the present power scenarios towards Distributed Generation. The growth of wind and photovoltaic power generation has increased rapidly [1-2]. Both wind and solar are 
considered as prospective energy sources individually; however, hybrid systems have the potential of providing better quality and reliability to the customers. Distributed generation also reduces the need of transmitting power over long distances. A new form of small, independent power system interface known as micro-grid has become popular nowadays. Small modular sources like wind, photovoltaic, fuel cells, batteries, electrolyzer, and diesel generators can be connected to form a micro-grid [3-11].

A micro-grid is more suitable for isolated or standalone systems as renewable energy is the most viable source of energy. A rapidly growing interest for micro-grids was observed in recent years. Micro-grid can be controlled to manage the power in the system with or without power exchange with the utility grid by appropriate control schemes. Micro-grids can be operated in different modes: grid mode and local mode. In grid mode, energy is exchanged between the utility grid and the micro-grid to balance the local demand and generation. Basically in this mode, the utility grid absorbs or provide power to the micro-grid based on the demand. In local mode, the micro grid balances the power independent of the utility grid [12]. In local mode, the utility grid does not provide or absorb any power from the micro-grid. In this mode, the micro-grid depends only on the renewable energy (wind power and solar power). In local mode, if demand of micro-grid is greater than the local generation system (WT and SP) dc loads can be controlled for power load shedding to balance the power in the whole system. The proposed CSU controls the dc load for load shedding to maintain the stability of the system.

Power management is one of the major issues in micro-grids where variations of the loads and generations are significant in the system. Various researches are going on the micro-grid power management issues. Several studies have been reported to balance the power in micro-grid in recent studies [13-15]. Power control and management in 
hybrid ac-dc micro-grid is discussed in [16]. Real and reactive power control strategies of electronically interfaced multiple generation micro-grid systems are addressed in [17]. Power management and power flow control between utility and micro-grid through back-to-back converters has been shown in [18]. Voltage-power droop control scheme is presented in [19] which allow several voltage source converters (VSCs) to operate in parallel in a micro-grid system. Reliability is another major issue to be ensured in a micro-grid system [20]. In the existing work of micro-grids it has been seen that a common power converter connects the ac and dc bus. Using a single power converter in the micro-grid reduces the reliability of the micro-grid. If due to any transient fault or any disturbance the single power converter stops operating or shuts down for maintenance then a part of micro-grid has to be disconnected which surely reduces the reliability of the micro-grid system. Also a micro-grid operates in local and grid modes so the power needs to be balanced always. In this paper, a multiple converter scheme is proposed where multiple converters operate in the micro-grid. Instead of using one large size power converter unit, multiple small units are utilized. So, according to the generation, one single converter would operate and if the rated power of the unit is exceeded then the alternate converter unit would be enabled. This scheme not only increases the reliability of the system, but also increases the efficiency of the converters. The present schemes in the existing papers focus on different methods which are complex and expensive. In this paper, the proposed central supervisory control scheme, controlling and calculation of multiple converters are done which is simple and cost effective. The reference signals generated from the controller needs to be sent using the communication system which is part of the modern smart micro-grids. The proposed scheme also ensures the power management during local and grid modes where the grid power is controlled during grid mode and dc load is controlled during local mode in addition with the multiple converter control. 
Wind power is considered to be one of the most promising renewable sources of energy; however the generated electrical power has randomly varying and intermittent characteristics. The smoothing of the wind power fluctuations has become one of the major issues of micro-grid systems. Wind power fluctuation can be smoothened up to certain range by the blade pitch angle control of the wind turbine [21]. It is reported in [22-23] that superconducting magnetic energy storage (SMES) system can be used to smoothen the wind power fluctuation. A flywheel energy system is proposed in [24-25]. Energy capacitor system (ECS) composed of power electronic devices and electric double layer capacitors (EDLC) has been proposed for smoothing the wind power fluctuation in [26-28]. A battery energy storage system (BESS) [29] has been reported to smooth the power fluctuation. Also, if BESS is integrated with STATCOM, then this integration technique can provide both real and reactive power quite well [30]. Sodium sulfur (NAS) battery is an advanced secondary battery developed by Tokyo Electric Power Company (TEPCO) and NGK Insulators, Ltd. since 1983 [31]. It is reported in [31] that NAS battery is the most suitable one for use in large scale battery energy storage system due to its long life cycle and outstanding efficiency.

This paper presents the power management of an ac-dc hybrid micro-grid system by incorporating a generic centralized supervisory control scheme. The major feature of this paper is mentioned below:

1. In local mode, the CSU generates reference signals for the power converters and dc loads. The reference signals are generated in such a way that the power is balanced in the system.

2. In grid mode, CSU generates reference signals for power converters which indirectly control the power flow between utility grid and micro-grid ensuring power balance. 
3. In both modes, reference signals are generated for multiple power converters. Alternate power converters are enabled if any individual power converter rating is crossed controlling the real power and terminal voltage of the system.

4. Sodium sulfur (NAS) battery energy storage system is integrated with a fixed speed wind turbine generator system to smooth the output power fluctuation of the wind farm using real wind speed data.

\section{Proposed Micro-grid System Configuration}

A hybrid micro-grid system is used in this paper which is extracted from the benchmark system of the IEEE standard 399-1997 [32], with some modifications to allow the grid and islanded operation of micro-grid as shown in Fig. 1. The proposed system consists of an ac bus on the left and dc bus on the right side. The ac and dc buses have corresponding sources, loads, and energy storage systems.

Fig. 1. Proposed ac-dc hybrid micro-grid model system

On the ac bus, seven induction generators of 1MW driven by wind turbines and two ac loads are connected. Capacitor banks are used at the induction generator terminals to maintain unity power factor operation at the rated wind speed. A Sodium sulfur battery energy storage system (NAS BESS) is connected at the common terminal point of the wind generators. On the dc bus photovoltaic system, energy storage system (ESS), and three dc loads are connected. ESS at the dc bus is used to provide backup power to the dc loads if required which is not included in this paper. Two energy storage systems are needed for bigger plants where the dc loads are critical loads. The ac bus is connected to the utility grid through a transmission line TL1 and a transformer. The photovoltaic system is connected with the dc bus via dc-dc converter to extract maximum power. In between the ac bus and dc bus multiple power converters, connected in parallel are used. The power converters allow the transfer of power 
between the dc and the ac sides. In the simulation, two power converters are used with individual rating of $2.5 \mathrm{MW}$. The power converter modeled in the simulation can also operate in DC/AC mode (inverter mode), however, due to avoid confusion and for better understanding of the main focus of the paper, any case with inverter mode is not included in the manuscript.

\section{Component Modeling of the Micro-grid System}

\subsection{Wind Turbine Modeling}

Wind turbines capture kinetic energy from the wind and convert it into electrical energy. The wind turbine output torque and extracted power can be expressed by the following equations [33]:

$P_{m}=\frac{1}{2} \cdot \rho C_{P}(\lambda) A V_{W}{ }^{3}[W]$

where $\rho$ is the air density $\left[\mathrm{kg} / \mathrm{m}^{3}\right], \mathrm{R}$ is the radius of the blade $[\mathrm{m}], \mathrm{V}_{\mathrm{W}}$ is the wind speed $[\mathrm{m} / \mathrm{s}], \mathrm{A}$ is the cross sectional area of the turbine $\left[\mathrm{m}^{2}\right] . \mathrm{C}_{\mathrm{P}}(\lambda, \beta)$ is the power coefficient given by

$C_{P}(\lambda, \beta)=\frac{1}{2} \cdot\left(\Gamma-0.02 \beta^{2}-5.6\right) e^{-0.17 \Gamma}$

where, $\quad \Gamma=\frac{R(3600)}{\lambda(1609)}$ and $\lambda=\frac{\omega_{m} R}{V_{w}}$ is the tip speed ratio.

$\omega_{\mathrm{m}}$ represents the rotor mechanical speed and $\beta$ is the pitch of the rotor blades. Pitch control allows limiting of the generator power at wind speed higher than the rated.

\subsection{Photovoltaic System Modeling}

Photovoltaic systems convert solar radiation into electrical energy. A practical Photovoltaic system can be modeled by a current source in parallel with a diode and a 
combination of a series resistance and a parallel resistance [34]. The current source represents the photo current, which is a function of incident solar radiation and temperature. The diode represents the reverse saturation current due to the $p-n$ junction of the solar cell while the resistances account for the losses [34].

\subsection{NAS Battery}

Sodium sulfur (NAS) battery model consists of a variable voltage source with a series resistance. The voltage is modeled to drop linearly with the state of charge (SOC) of the battery. Assuming that the battery charge is at $65 \%$, the battery voltage is given by (3) where $V_{0}$ is the voltage of the open circuited fully charged battery [31]. The voltage drop across the battery resistance is assumed to be a constant percentage of the battery voltage as shown in (3).

$V_{\text {batt }}=0.95 \times V_{0}$

$I R_{N A S}=V_{\text {batt }} \times 0.05$

In this work detailed switching model is considered instead of time averaged model; therefore, the proposed model is simplified a little to speed up the simulation. The parameters of the proposed micro-grid system are shown in Table I. The total ac generation is chosen as $7 \mathrm{MW}$. The parameters of the induction generators used are given in Table II. The NAS battery energy storage system (NAS BESS) is rated at 4MW. A fixed reference of 5MW is used for smoothing the output power fluctuation of the wind farm. The photovoltaic system generates a constant $0.5 \mathrm{MW}$.

\section{Power Smoothing Control Scheme using NAS Battery}

The wind power smoothing is performed by the NAS battery energy storage system at the terminal point of the wind turbine generators. The schematic diagram of the integrated NAS BESS is shown in Fig. 2. The total capacity of the sodium sulphur 
battery energy storage system is $4 \mathrm{MW} / 2.857 \mathrm{MWh}$. The voltage controlled pulse width modulation based voltage source inverter is used in the system along with dc-dc buck/boost converter. The voltage controlled voltage source inverter (VC-VSI) controls the terminal voltage and maintains it at $1 \mathrm{pu}$. It also controls the dc link voltage between the VC-VSI and dc-dc buck/boost converter. The control strategy of the dc-dc buck boost converter is shown in Fig. 3. The error signal between the line power, $\mathrm{P}_{\text {line, }}$ (shown in Fig. 2) and reference (smooth) power is fed to the PI controller.

Fig. 2. Schematic diagram of Integrated NAS BESS

Fig. 3. Control block of the dc-dc buck/boost converter.

\section{Generic Centralized Supervisory Control Strategy}

Generic centralized supervisory control strategy based on parallel connected multiple power converters is proposed in this paper, which is a novel feature of this study. The control scheme is called generic as it is applicable to wide range of loading conditions. The central supervisory unit is designed based on the control scheme which generates the necessary command signals to perform power management in the ac-dc hybrid micro-grid system. The CSU also supervises the command signals to real and reactive power controllers of the individual power converter unit, as detailed in the following section.

\subsection{Central Supervisory Unit (CSU)}

The central supervisory unit is the core of the ac-dc hybrid micro-grid system. The CSU is designed for both the grid and local modes. The main focus of this control scheme is to ensure power management in the system and control the multiple power converters during both cases. In local mode, power management is ensured by controlling the dc loads. In Fig. 1, the proposed model system consists of multiple power converters and three dc loads. For this mode, the consumption of dc loads can be 
controlled to maintain power management in the system. Multiple power converters are controlled by controlling the real power. For grid mode operation, only real power through the multiple power converters is controlled. This indirectly controls the power flow between utility grid and micro-grid. The terminal voltage at the converter is controlled for both modes. Figure 4(a) shows the basic diagram of the central supervisory unit for both operating modes.

Fig. 4. (a) Central supervisory unit for local mode and grid mode (b) control scheme of real and reactive power through individual power converter.

During local mode operation, CSU generates command signal for the total dc loads, i.e. PLDCT. The CSU also generates, for both modes, the real power command signals $\mathrm{P}_{\mathrm{C} 1}, \mathrm{P}_{\mathrm{C} 2}$ up to $\mathrm{P}_{\mathrm{Cn}}$ for the power converters. The real power through each power converters is adjusted according to the demand. For example, if the rated power of each power converter is $2.5 \mathrm{MW}$ and total power passing through the power converters is 2 MW then the $1^{\text {st }}$ converter operates. If the total power passing through the power converters is $3 \mathrm{MW}$ then the $1^{\text {st }}$ and $2^{\text {nd }}$ converters operate. If total power through the power converters is $5.5 \mathrm{MW}$ then the $1^{\text {st }}, 2^{\text {nd }}$ and $3^{\text {rd }}$ converters operate. This aims to improve the system efficiency. The command signals generated from the CSU in grid mode automatically control the power flow between utility grid and micro-grid. Figure 4(b) shows the control block diagram of individual small power converter units, where phase lock loop (PLL) provides the angle $\theta_{P L L}$ for the abc-to-dq0 and dq0-to-abc transformation. The d-axis current controls the real power while the q-axis current controls the reactive power of the converter.

\subsubsection{Local Mode}

In local mode, ac loads connected in the ac-dc hybrid micro-grid system and the smoothened wind power are taken as input to the CSU. The details of the control scheme for local mode are shown in Fig. 5(a) which is the core work for local mode. In 
order to calculate the power flow through the multiple power converters, first the ac loads in the micro-grid system are calculated in the first three steps. $\mathrm{P}_{\text {LAC }}$ indicates the individual ac load demand in the system, $\mathrm{G}$ is the conductance, $\mathrm{V}_{\mathrm{tL}}$ is terminal voltage at the ac load and $\mathrm{P}_{\mathrm{G}}$ is the base power. $\mathrm{P}_{\mathrm{LACT}}$ indicates the total ac load demand in the system. $\mathrm{P}_{\text {Total }}$ indicates the amount of the power to be passed through the total converters. In practice, the total ac load can be measured from the system.

Fig. 5. Generic centralized control strategy of CSU (a) local mode (b) grid mode.

Comparing to the value of $\mathrm{P}_{\text {Total }}$ with the individual converter unit rating, the command signals, $\mathrm{P}_{\mathrm{C} 1}, \mathrm{P}_{\mathrm{C} 2}$ and $\mathrm{P}_{\mathrm{Cn}}$ for the multiple power converters are generated in the system. The symbol $\mathrm{n}$ determines the number of multiple converters used in the system. The powers through the total converters are summed with dc source of photovoltaic system to obtain the total power flow to the dc loads i.e. $\mathrm{P}_{\text {Total }}+\mathrm{P}_{\mathrm{PV}}$. The command signal for changing total dc loads $\mathrm{P}_{\mathrm{LDCT}}$ is generated from CSU. The total dc load is changed by ESS connected at the dc bus depending on the generated command signal.

\subsubsection{Grid Mode}

For this case, the power management through control of the power flow between utility grid and micro-grid system is shown in Fig. 5(b) which is the core work for grid mode. In this case, ac and dc load consumptions in the ac-dc hybrid micro-grid system are taken as input to the central supervisory unit. The total real power $\mathrm{P}_{\text {Total, }}$ into the power converters is calculated where $\mathrm{P}_{\text {Total }}=\mathrm{P}_{\mathrm{LDC}-\mathrm{TOTAL}}-\mathrm{P}_{\mathrm{PV}}$ and it is compared with the rating of the small unit power converter $\mathrm{P}_{\text {Rated. }} \mathrm{P}_{\text {LDC-TOTAL }}$ indicates the total dc load consumption and $\mathrm{P}_{\mathrm{PV}}$ indicates the power generated from the photovoltaic system. Through calculation of the amount of power to be passed through the power converters, 
the utility grid power is automatically controlled by the CSU ensuring the power management in the system.

\section{Simulation Results}

To verify the effectiveness of the proposed system, simulation analysis has been performed. Real wind speed data measured in Hokkaido Island, Japan is shown in Fig. 6. Wind farm aggregated model is considered in the simulation. The simulations have been performed by using PSCAD/EMTDC [35].

Responses of the fluctuating output power of the wind farm, along with the smooth line power, photovoltaic output power, real power and reactive power provided by the voltage source inverter with NAS battery ESS are shown in Figs.7 and 8. The blue color trace in Fig. 7 shows the fluctuating wind farm power output and an almost straight line in brown color shows the smooth wind farm output $\mathrm{P}_{\text {line }}$ at $5 \mathrm{MW}$. DC link voltage of NAS BESS inverter is shown in Fig. 9. Terminal voltage at PCC of NAS BESS and grid side is shown in Fig. 10. Fig. 8 (Real and reactive power of VSI with BESS) indicates the performance of the dc-dc converter. As it can be seen from Fig. 3 (Control block of the dc-dc buck/boost converter) that dc-dc converter controls the $\mathrm{P}_{\text {line }}$ with reference to $\mathrm{P}_{\text {ref }}$ and the result of controlled $\mathrm{P}_{\text {line }}$ is depicted in Fig. 7 (smoothen power). Basically the whole BESS including VSI and dc-dc converter controls the terminal voltage (Fig. 10), dc link voltage (not shown in the simulation results) and smoothen power (Fig. 7). (2) The wind power $\mathrm{P}_{\text {line }}$ which is the smoothen power is controlled by the dc-dc converter. The wind power (the output of the wind farm before connecting point with battery energy storage system) depends on wind speed. As it can be seen from Fig. 6 and 7, that PIG wind farm actually follows the pattern of wind speed from Fig. 6. However, the smoothen power $\mathrm{P}_{\text {line }}$ follows the reference $\mathrm{P}_{\text {ref }}$ (Fig. 3). The smoothen power is controlled because the fluctuated wind power $\mathrm{P}_{\mathrm{IG}}$ wind farm might 
cause fluctuation in the frequency of the system. Specially during change over from grid connected to islanding mode and vice-versa, the micro-grid frequency may result to fluctuation because of fluctuated wind power. The smoothen power from the battery energy storage system keeps the systems stable specially during any faulty or critical condition like islanding mode. Detailed control and simulation results except the major part of the dc-dc converter are not shown as it is not main focus of the paper hence it is an additional part. These responses show the effectiveness of the battery model in terms of smoothing the fluctuating output power of the aggregated wind farm. The effectiveness of the generic centralized supervisory control scheme to perform the power management is tested for both grid - and local modes.

Fig. 6. Wind speed

Fig. 7. Wind farm output and smoothen power

Fig. 8. Real and reactive power of VSI with BESS Fig. 9. DC link voltage of BESS

Fig. 10. Terminal voltage at PCC of NAS and grid

\subsection{Local Mode}

In section $\mathrm{V}$, it is explained that for local mode operation, the CSU, generates the command signals for the multiple converters and dc loads to ensure the power management in the micro-grid system. To verify the effectiveness of central supervisory unit a test case, involving a wide range of two ac loads $\mathrm{P}_{\mathrm{LAC} 1}$ and $\mathrm{P}_{\mathrm{LAC} 2}$ is considered. The ac load values, the smooth power $\mathrm{P}_{\text {line }}$ and $\mathrm{P}_{\mathrm{PV}}$ are the known values to the central supervisory unit. The CSU then calculates the real power flow required through the two power converters $\mathrm{P}_{\mathrm{PC} 1}, \mathrm{P}_{\mathrm{PC} 2}$ and total value of the dc loads $\mathrm{P}_{\mathrm{LDCT}}\left(\mathrm{P}_{\mathrm{LDC} 1}+\mathrm{P}_{\mathrm{LDC} 2}+\mathrm{P}_{\mathrm{LDC} 3}\right)$. All these values are summarized in Table III. 
The generated command signals for the two power converters considered in the simulation, $\mathrm{P}_{\mathrm{C} 1}$ and $\mathrm{P}_{\mathrm{C} 2}$ are shown in Fig. 11. Figure 12 depicts the real power through the power converters. It is observed from this response that the power through the two power converters follow the command signals $\mathrm{P}_{\mathrm{C} 1}$ and $\mathrm{P}_{\mathrm{C} 2}$ (Fig. 11). Figure 13 shows the total ac and de loads, $\mathrm{P}_{\text {LACT }}$ and $\mathrm{P}_{\mathrm{LDCT}}$ in the system. It can also be observed from the system that the CSU effectively adjusts the dc loads, $\mathrm{P}_{\text {LDCT }}$ to ensure power management.

Fig. 11. Command signal for converters in CSU for local mode

Fig. 12. Real power through power converters for local mode

Fig. 13. Ac and dc loads for local mode

\subsection{Grid Mode}

In this case, the proposed control scheme ensures the power management in the ac-dc hybrid micro-grid system by the power flow control between utility grid and micro-grid system. As for the previous mode, the effectiveness of the CSU is verified with a test case where, a wide range of two ac loads $\mathrm{P}_{\mathrm{LAC} 1}, \mathrm{P}_{\mathrm{LAC} 2}$ and three dc loads $\mathrm{P}_{\mathrm{LDC} 1}, \mathrm{P}_{\mathrm{LDC} 2}, \mathrm{P}_{\mathrm{LDC} 3}$ are considered. These values and $\mathrm{P}_{\mathrm{PV}}$ are the known variables to the central supervisory unit. The required real power flow through the two power converters is then calculated by the CSU hence automatically establishing the power flow between utility grid and micro-grid system. All these values are summarized in Table IV.

Figure 14 depicts the command signals $\mathrm{P}_{\mathrm{C} 1}$ and $\mathrm{P}_{\mathrm{C} 2}$ generated from the CSU. It is seen from the response that when both of the power converters are turned on, the total power through the converters is divided into two. In Fig. 15, the utility grid power is shown which is controlled by the central supervisory unit. It can be seen from Fig. 16 that the power through the two power converters follows the reference signals. Total ac and dc loads are shown in Fig. 17. 
Fig. 14. Command signal for converters in CSU for grid mode

Fig. 15. Power flow control between grid and micro-grid for grid mode

Fig. 16. Real power through power converters for grid mode

Fig. 17. Ac and dc loads for grid mode

\subsection{Real time load}

A real time ac load pattern, $\mathrm{P}_{\mathrm{LACT}}$ is considered for the local mode. The load pattern represents the load consumption of one commercial building. The real powers $\mathrm{P}_{\mathrm{C} 1}$ and $\mathrm{P}_{\mathrm{C} 2}$ through the power converters are shown in Fig. 18. The central supervisory unit performs the dc load control so that the power management is ensured in the system. The total ac loads $\mathrm{P}_{\mathrm{LACT}}$ and the total dc loads $\mathrm{P}_{\mathrm{LDCT}}$ are shown in Fig. 19.

Fig. 18. Real power through power converters using real time ac load for local mode Fig. 19. Real time ac load and adjusted dc loads for local mode

Similar to the previous case, a real time ac load pattern $\mathrm{P}_{\mathrm{LACT}}$ and real time dc load pattern $\mathrm{P}_{\text {LDCT }}$ are considered for the grid mode. The load consumption of a refrigerator is used in this case for the analysis. The real time ac and dc loads are shown in Fig. 20. The power flow between utility grid and micro-grid is shown in Fig. 21 which is controlled by the central supervisory unit. Figure 22 depicts the real power $\mathrm{P}_{\mathrm{C} 1}$ and $\mathrm{P}_{\mathrm{C} 2}$ through the power converters.

Fig. 20. Real time ac load and real time dc loads for grid mode

Fig. 21. Power flow control between grid and micro-grid for grid mode with real time ac and de load

Fig. 22. Real power through power converters using real time ac and dc load for grid mode

\section{Conclusion}

In this paper, a generic centralized supervisory control scheme has been proposed to ensure the power management in the ac-dc hybrid micro-grid system. The 
effectiveness of the control strategy has been verified for grid and local modes of operation with wide range of load and real time load. The significance of the paper is mentioned below:

- Large scale integration of wind farm and simple photovoltaic system in microgrid extracted from the benchmark system of the IEEE standard 399-1997 with modifications.

- The multiple converters are controlled precisely for both grid and local modes with real time loads.

- The proper utilization of the small units of the power converters increases the efficiency of the converter units.

- The grid power is controlled during grid mode. The dc loads are controlled during local mode. Both functions are operated only be controlling the power converter reference which is less complex and less expensive.

- The dc load controlling refers to the power curtailment which is an option in the event of a worst case scenario of micro-grids. But integration of ESS at dc side, can solve the power curtailment issue by controlling the reference of the ESS at dc side from proposed CSU which is again simple and less expensive.

- The terminal voltage of the micro-grid is controlled by reactive power compensation from the power converter.

- Integration of NAS BESS performs smoothing of power which maintains the frequency of the system throughout the grid and local modes.

It can be concluded that the proposed ac-dc hybrid micro-grid system integrated with NAS BESS along with the incorporation of the centralized supervisory control strategy turns the system into an enhanced stable and reliable hybrid system ensuring the power management in the system. 


\section{References}

[1] The Global Wind Energy Council, Global Wind Report, Annual market update 2010. Available: http://www.gwec.net/

[2] Trends in Photovoltaic Applications: Survey Report of Selected IEA Countries between 1992 and 2004, International Energy Agency Photovoltaics Power Systems Programme (IEA PVPS), Sep. 2005.

[3] N. K. Ardeshna and B. H. Chowdhury, Optimizing Micro-grid Operations in the Presence of Wind Generation, Power Symposium, NAPS'08, 28-30 Sept. 2008.

[4] Anne-Marie Borbely and Jan F. Kreider, Distributed Generation: Power Paradigm for the New Millennium; CRC Press., 2001.

[5] R. H. Lasseter, MicroGrids, PES Winter Meeting, vol. 1, pp. 305-308, 2002.

[6] X. Liu, P. Wang and P. C. Loh, A Hybrid AC/DC Microgrid and Its Coordination Control, IEEE Trans. Smart Grid, Vol. 2, No. 2, (June 2011), 278-286.

[7] Y. Ito, Z. Yang and H. Akagi, DC micro-grid based distribution power generation system, Proc. IEEE Int. Power Electron. Motion Control Conf., Aug. 2004, Vol. 3, 1740-1745.

[8] Y. Zoka, H. Sasaki, N. Yorino, K. Kawahara and C.C. Liu, An interaction problem of distributed generators installed in a MicroGrid, Proc. IEEE Elect. Utility Deregulation, Restructuring. Power Technol., Apr. 2004, vol. 2, 795-799.

[9] R. H. Lassester and P. Paigi, Microgrid: A conceptual solution, Proc. IEEE $35^{\text {th }}$ PESC, Jun. 2004, vol. 6, 4285-4290.

[10] C. K. Sao and P. W. Lehn, Control and power management of converter fed MicroGrids, IEEE Trans. Power Syst., vol. 23, no. 3, (Aug. 2008), 1088-1098. 
[11] T. Logenthiran, D. Srinivasan and D. Wong, Multi-agent coordination for DER in MicroGrid, in Proc. IEEE Int. Conf. Sustainable Energy Technol., (Nov. 2008), $77-82$

[12] A. Burgio, D.Menniti and N. Sorrentino, The reliability studies of a novel integrated configuration for micro-grids, International conference on Electric Utility Deregulation and Restructuring and Power Technologies, (6-9 April 2008), 26342639.

[13] C. M. Colson, and M. Hashem Nehrir, Comprehensive Real-time Microgrid Power Management and Control With Distributed Agents, IEEE Trans. Smart Grid, Vol. 4, No. 1, (March 2013), 617-627.

[14] A. Solanki, A. Nasiri, V. Bhavaraju, T. Abdullah, and D. Yu, A new control method for microgrid power management, 2013 International Conference on Renewable Energy Research and Applications (ICRERA), (20-23 Oct. 2013), 1212 $-1216$.

[15] Le Yi Wang, Michael P. Polis, Caisheng Wang, Feng Lin, and George Yin, Voltage robust stability in microgrid power management, 2013 IEEE 52nd Annual Conference on Decision and Control (CDC), (10-13 Dec. 2013), 6928 - 6933.

[16] Navid Eghtedarpour and Ebrahim Farjah, Power Control and Management in a Hybrid AC/DC Microgrid, IEEE Trans. Smart grid, Vol. 5, No. 3, (MAY 2014), 1494-1505.

[17] F. Katiraei and M. R. Iravani, Power Management Strategies for a Micro-grid with Multiple Distributed Generation Units, IEEE Trans. Power systems, Vol. 21, No. 4, (Nov. 2006), 1821-1831. 
[18] R. Majmunder, A. Ghosh, G. Ledwich and F. Zare, Power Management and Power Flow Control With Back-to-Back Converters in a Utility Connected Microgrid, IEEE Trans. Power Systems, Vol. 25, No. 2, (May 2010), 821-834.

[19] C. K. Sao and P. W. Lehn, Control and Power Management of Converter Fed Microgrids, IEEE Trans Power Systems, Vol. 23, No.3, (Aug, 2008), 1088-1098.

[20] I. Bae and J. Kim, Reliability Evaluation of Customers in a Micogrid, IEEE Trans. Power Systems, Vol. 23, No.3, (Aug 2008), 1416-1422.

[21] T. Senjyu, R. Sakamoto, N. Urasaki, T. Funabashi, H. Fujita and H. Sekine, Output power leveling of wind turbine generator for all operating regions by pitch angle control, IEEE Trans. Energy Convers., vol. 21, no. 2, (Jun. 2006), 467-475.

[22] S. Nomura, Y. Ohata, T. Hagita, H. Tsutsui, S. Tsuji-Iio and R. Shimada, Wind farms linked by SMES systems, IEEE Trans. Appl. Supercond., vol. 15, no. 2, (Jun. 2005), 1951-1954.

[23] F. Zhou, G. Joos, C. Abbey, L. Jiao and B.T. Ooi, Use of large capacity SMES to improve the power quality and stability of wind farms, in Proc. IEEE Power Eng. Soc. Gen. Meeting, vol. 2, (Jun. 2004), 2025-2030.

[24] R. Takahashi, Wu. Li, T. Murata and J. Tamura, An application of flywheel energy storage system for wind energy conversion, Proc. Int. Conf. Power Electron. Drives Syst. (PEDS 2005), 932-937.

[25] R. Cardenas, R. Pena, G. Asher and J. Clare, Power smoothing in wind generations systems using a sensorless vector controlled induction machine driving a flywheel, IEEE Trans. Energy Convers., vol. 19, no. 1, (Mar. 2004), 206-216. 
[26] R. L. Spyker and R. M. Nelms, Optimization of double-layer capacitor arrays, IEEE Trans. Ind. Appl., vol. 36, no. 1, (Jan./Feb. 2000), 194-198.

[27] T. Kinjo, T. Senjyu, N. Urasaki and H. Fujita, Output leveling of renewable energy by electric double-layer capacitor applied for energy storage system, IEEE Trans. Energy Convers., vol. 21, no. 1, (2006), 221-227.

[28] S. M. Muyeen, R. Takhashi, T. Murata and J. Tamura, Integration of an Energy Capacitor System With a Variable-Speed Wind Generator, IEEE Trans. Energy Convers., vol. 24, no. 3, (Sept. 2009), 740-749.

[29] S.M. Muyeen, M.H. Ali, R. Takahashi, T. Murata, and J. Tamura, Wind generator output power smoothing and terminal voltage regulation by using STACOM/BESS, in power Tech, 2007 IEEE Lausanne, (1-5 July 2007), 1232-1237.

[30] S. M. Muyeen, J. Tamura, and T. Murata, Stability Augmentation of a Gridconnected Wind Farm, Springer-Verlag London, ISBN 978-1-84800-315-6, (October 2008).

[31] M. Kamibayashi and K. Tanaka, Recent Sodium Sulfur Battery Applications, Proc. IEEE PES Transmission and Distribution Conference and Exposition, USA, 2001, Vol. 2, (28 Oct.-2 Nov. 2001), 1169-1173.

[32] F. Katiraei, M. R. Iravani and P.W. Lehn, Micro-Grid Autonomous Operation During and Subsequent to Islanding Process, IEEE Trans. On Power Delivery, Vol. 20, No 1, (January 2005).

[33] O. Wasynczuk etc, Dynamiac behavior of a class of wind turbine generators during random wind fluctuations, IEEE Trans. on Power Apparatus and Systems, Vol.PAS-100, No.6, (1981), 2854-2854. 
[34] G. Vachtsevanos and K. Kalaitzakis, A Hybrid Photovoltaic Simulator for Utility Interactive Studies, IEEE Trans. Energy Conversion, Vol. EC-2, No. 2, (June 1987), 227-231.

[35] PSCAD/EMTDC Manual, Manitoba HVDC Research Center, (1994).

TABLE I

MICRO-GRID PARAMETERS

\begin{tabular}{|l|l|}
\hline \multicolumn{1}{|c|}{ Parameters } & \multicolumn{1}{|c|}{ Value } \\
\hline Base MVA of each power converter & $2.5 \mathrm{MVA}$ \\
\hline Base voltage of each power converter & $3.6 \mathrm{kV} \mathrm{VLL}$ \\
\hline Base current of each power converter & $0.40093 \mathrm{~A}$ \\
\hline Resistance (TL1) & $0.26368 \Omega$ \\
\hline Inductance (TL1) & $0.0004326 \mathrm{H}$ \\
\hline Length (TL1) & $2.06 \mathrm{~km}$ \\
\hline Resistance (TL2) & $0.013312 \Omega$ \\
\hline Inductance (TL2) & $0.00002184 \mathrm{H}$ \\
\hline Length (TL2) & $104 \mathrm{~m}$ \\
\hline Total AC generation & $7 \mathrm{MW}$ \\
\hline Total DC generation & $0.5 \mathrm{MW}$ \\
\hline AC loads & Up to 4 MW \\
\hline DC loads & Up to $5 \mathrm{MW}$ \\
\hline DC bus voltage & $1.5 \mathrm{kV}$ \\
\hline DC link capacitance & \\
\hline NAS BESS power & \\
\hline
\end{tabular}


TABLE II

INDIVIDUAL IG PARAMETERS

\begin{tabular}{|l|c|}
\hline \multicolumn{1}{|c|}{ Generator Type } & IGs \\
\hline MW & 1 \\
\hline Stator resistance & 0.01 \\
\hline Rotor resistance $(\mathrm{pu})$ & 0.01 \\
\hline Leakage reactance $(\mathrm{pu})$ & 0.1 \\
\hline Magnetizing reactance $(\mathrm{pu})$ & 3.5 \\
\hline Rotor mutual reactance $(\mathrm{pu})$ & 0.12 \\
\hline Inertia constant $(\mathrm{sec})$ & 1.5 \\
\hline Voltage rating, $\left(\mathrm{kV} \mathrm{LL}_{\mathrm{LL}}\right)$ & 0.69 \\
\hline
\end{tabular}

TABLE III

KNOWN AND UNKNOWN VALUES TO THE CSU IN LOCAL MODE

\begin{tabular}{|c|c|c|c|c|c|c|c|c|}
\hline \multirow[t]{2}{*}{ Mode } & \multicolumn{4}{|c|}{ Known to the CSU } & \multicolumn{4}{|c|}{ Calculated by the CSU } \\
\hline & $\mathrm{P}_{\text {line }}$ & $P_{\text {LaC1 }}$ & $\mathrm{P}_{\mathrm{LAC2} 2}$ & $\mathrm{PPV}_{\mathrm{PV}}$ & $\mathrm{P}$ & $\mathrm{P}_{\mathrm{C} 1}$ & $\mathrm{P}_{\mathrm{C} 2}$ & $P_{\text {LDCT }}$ \\
\hline \multirow{7}{*}{$\begin{array}{l}\overline{\mathscr{J}} \\
. \\
.\end{array}$} & \multirow[t]{7}{*}{5} & 1.5 & 1.5 & \multirow[t]{7}{*}{0.5} & 2 & 2 & 0 & 2.5 \\
\hline & & 1 & 1 & & 3 & 1.5 & 1.5 & 3.5 \\
\hline & & 1.5 & 2 & & 1.5 & 1.5 & 0 & 2 \\
\hline & & 2 & 2 & & 1 & 1 & 0 & 1.5 \\
\hline & & 1.5 & 0 & & 3.5 & 1.75 & 1.75 & 4 \\
\hline & & 2 & 1 & & 2 & 2 & 0 & 2.5 \\
\hline & & 0 & 1.5 & & 3.5 & 1.75 & 1.75 & 4 \\
\hline
\end{tabular}


TABLE IV

KNOWN AND UNKNOWN VALUES TO THE CSU IN GRID MODE

\begin{tabular}{|c|c|c|c|c|c|c|c|c|c|c|}
\hline \multirow[t]{2}{*}{ Mood } & \multicolumn{6}{|c|}{ Known to the CSU } & \multicolumn{4}{|c|}{ Calculated by the CSU } \\
\hline & $\mathrm{P}_{\mathrm{LAC1}}$ & $\mathrm{P}_{\mathrm{LAC} 2}$ & $\overline{\mathrm{P}_{\mathrm{PV}}}$ & $\mathrm{P}_{\mathrm{LDC} 1}$ & $\mathrm{P}_{\mathrm{LDC} 2}$ & $\mathrm{P}_{\mathrm{LDC} 3}$ & $\mathrm{P}$ & $\mathrm{P}_{\mathrm{C} 1}$ & $\mathrm{P}_{\mathrm{C} 2}$ & $\mathrm{P}_{\mathrm{GRID}}$ \\
\hline \multirow{7}{*}{ 节 } & 1.5 & 1.5 & \multirow[t]{7}{*}{0.5} & 2 & 1.5 & 1 & 4 & 2 & 2 & 2 \\
\hline & 1 & 1 & & 3 & 1 & 0 & 3.5 & 1.75 & 1.75 & 0.5 \\
\hline & 1.5 & 2 & & 2 & 1.5 & 1.5 & 4.5 & 2.25 & 2.25 & 3 \\
\hline & 2 & 2 & & 0 & 1 & 1.5 & 2 & 2 & 0 & 1 \\
\hline & 1.5 & 0 & & 3 & 1.5 & .5 & 4.5 & 2.25 & 2.25 & 1 \\
\hline & 2 & 1 & & 2 & .5 & 1 & 3 & 1.5 & 1.5 & 1 \\
\hline & 1.5 & 1.5 & & 0 & 0 & .5 & 0 & 0 & 0 & -2 \\
\hline
\end{tabular}

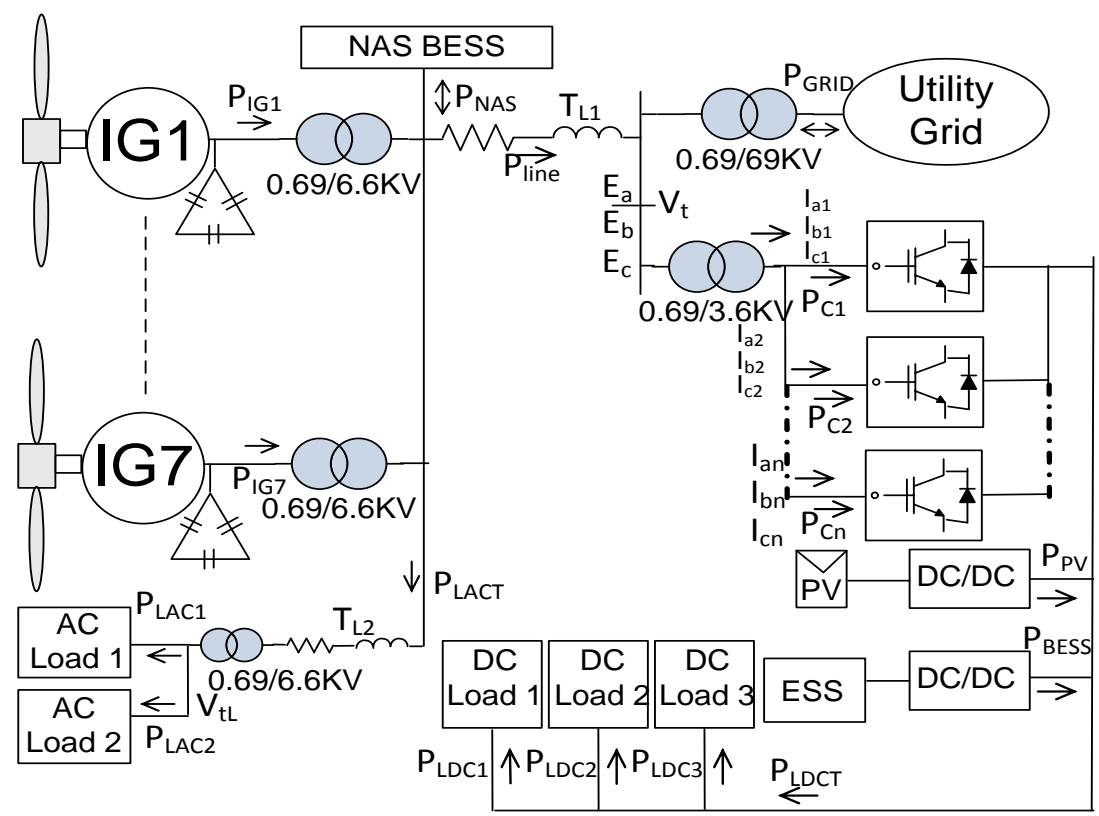

Fig. 1. Proposed ac-dc hybrid micro-grid model system 


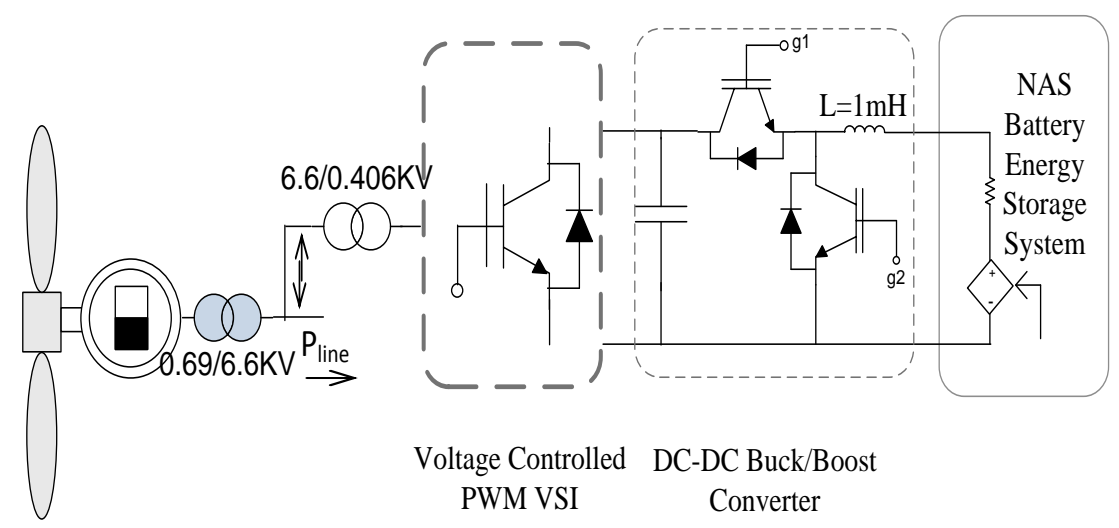

Fig. 2. Schematic diagram of Integrated NAS BESS

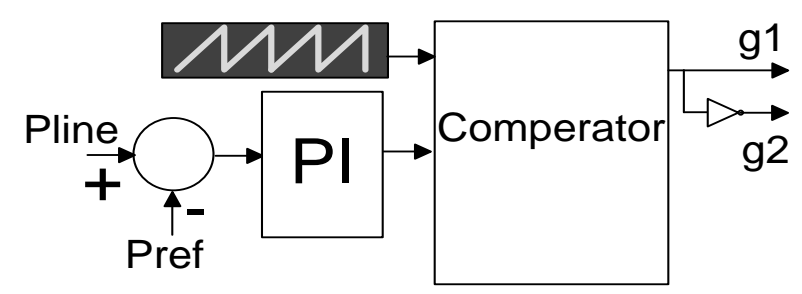

Fig. 3. Control block of the dc-dc buck/boost converter.

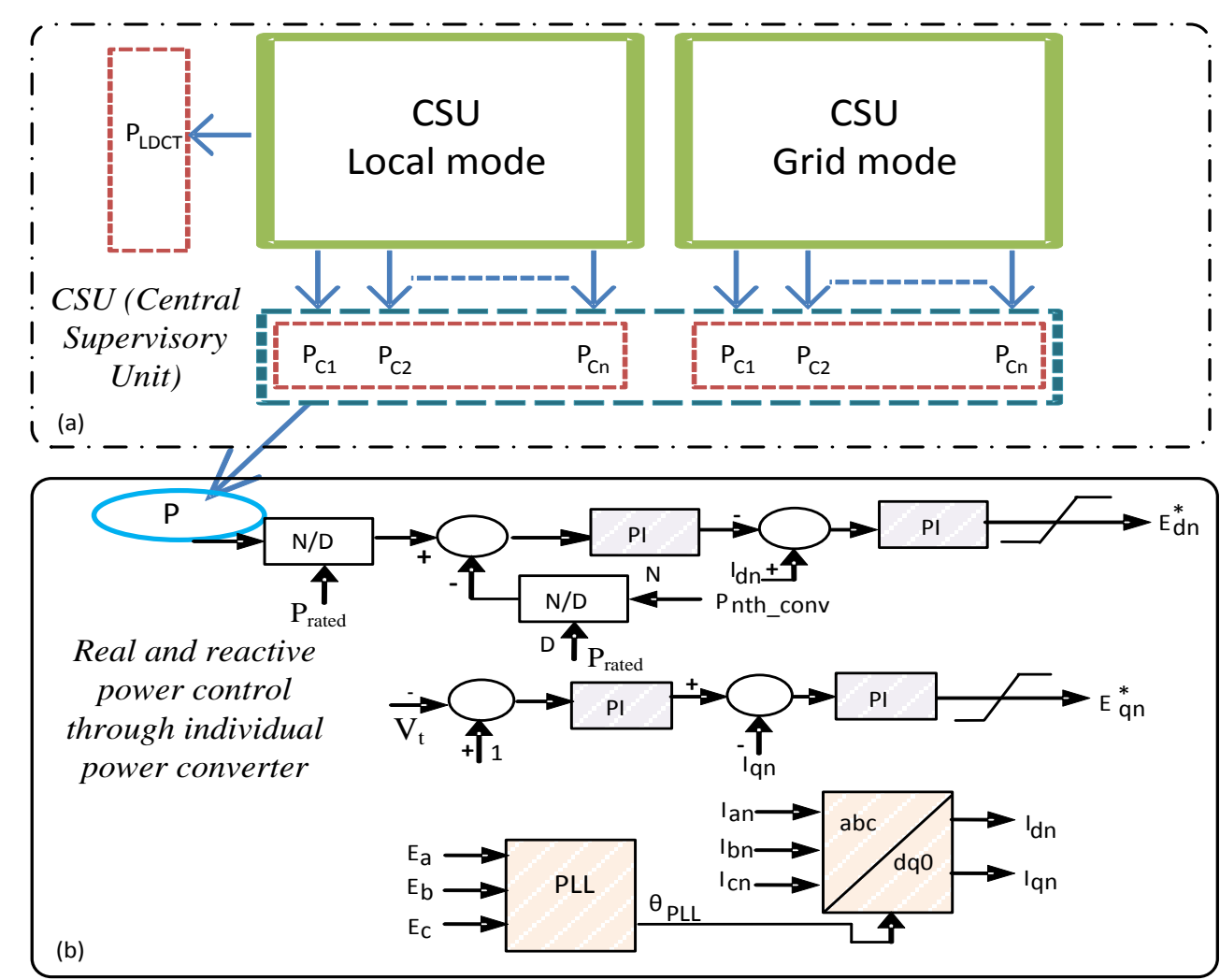

Fig. 4. (a) Central supervisory unit for local mode and grid mode (b) control scheme of real and reactive power through individual power converter 


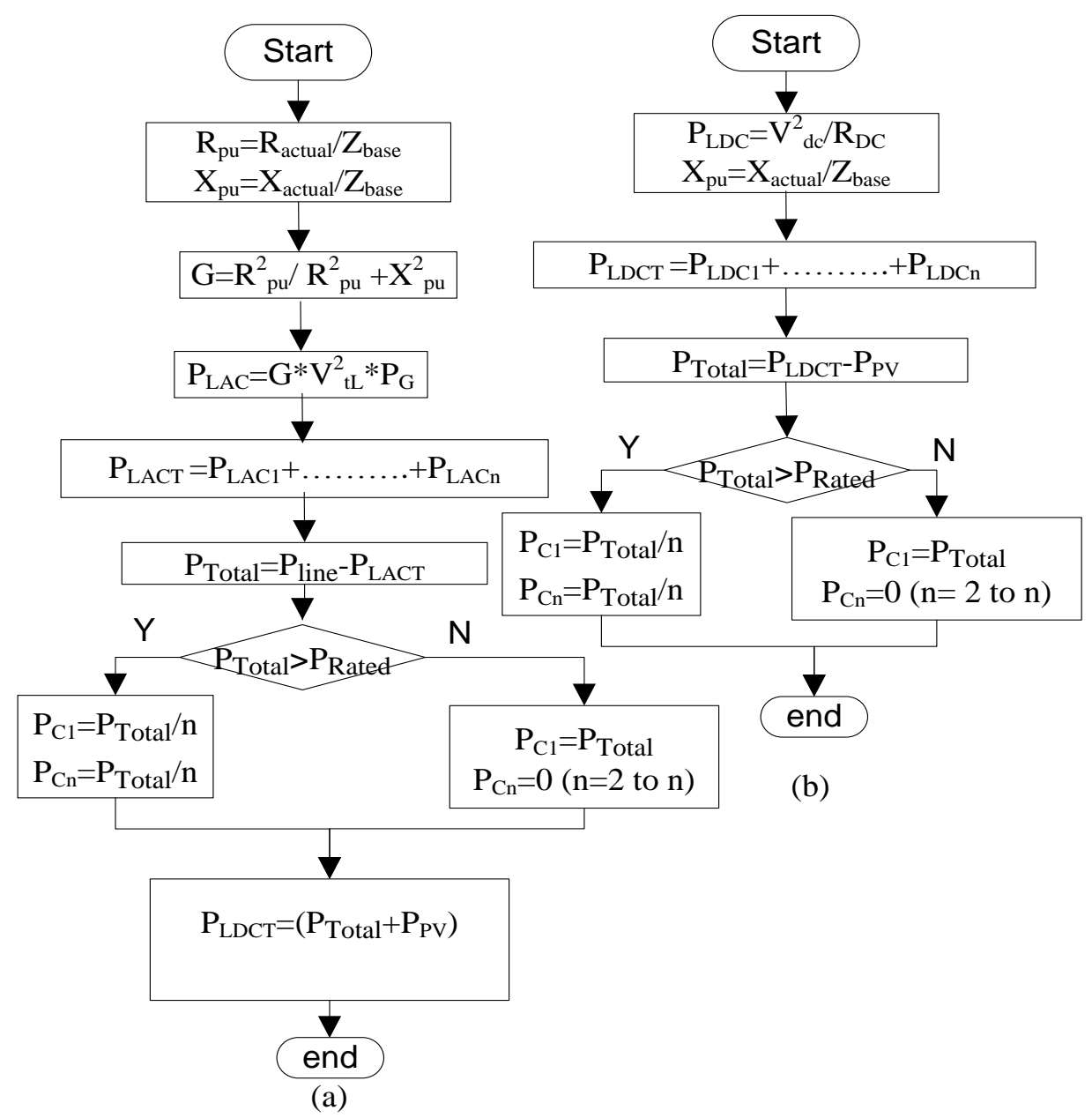

Fig. 5. Generic centralized control strategy of CSU (a) local mode (b) grid mode.

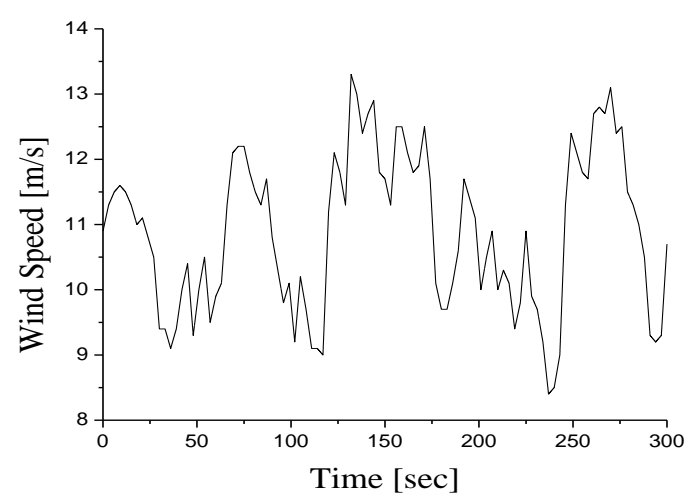

Fig. 6. Wind speed

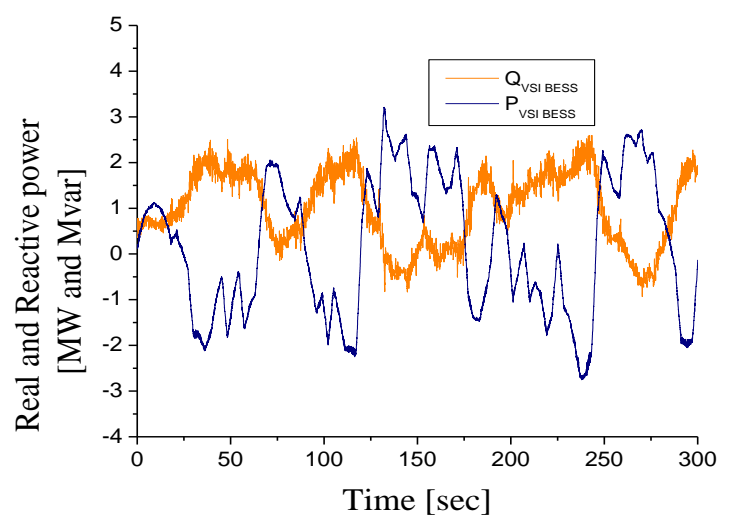

Fig. 8. Real and reactive power of VSI with BESS

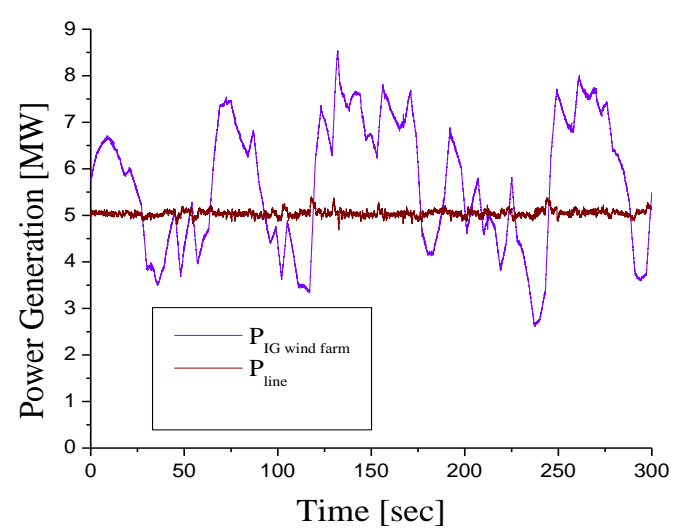

Fig. 7. Wind farm output and

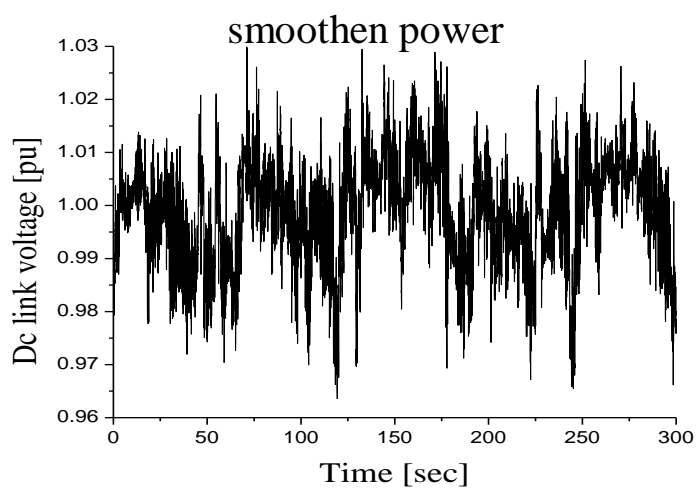

Fig. 9. DC link voltage of BESS 


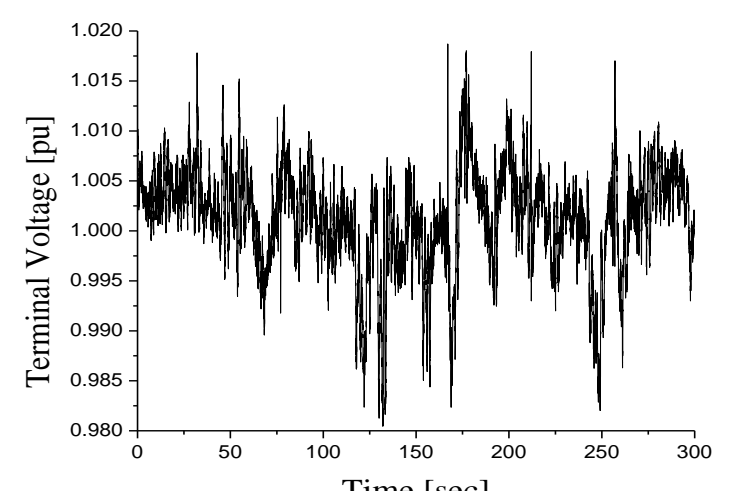

Fig. 10. Terminal voltage at PCC of NAS and grid

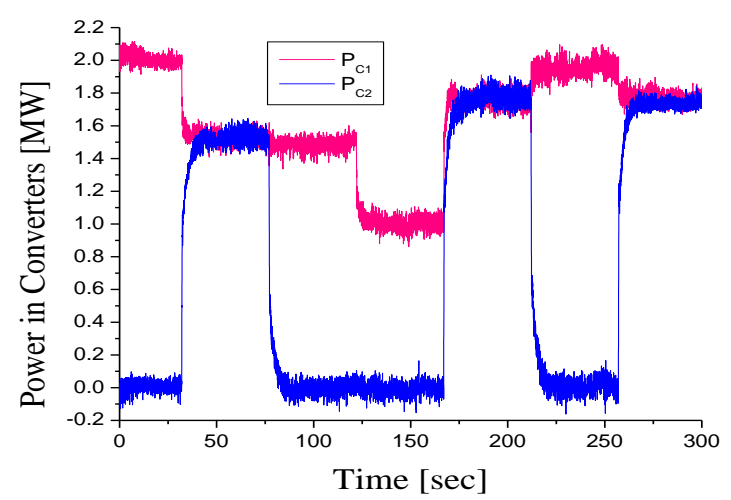

Fig. 12. Real power through power converters for local mode

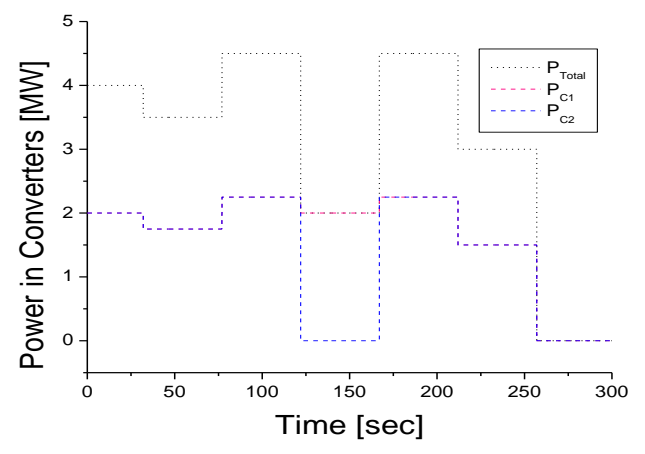

Fig. 14. Command signal for converters in CSU for grid mode

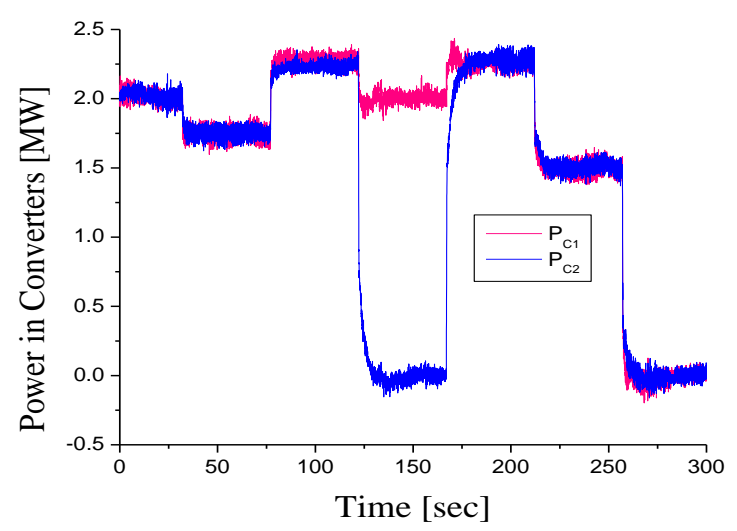

Fig. 16. Real power through power converters for grid mode

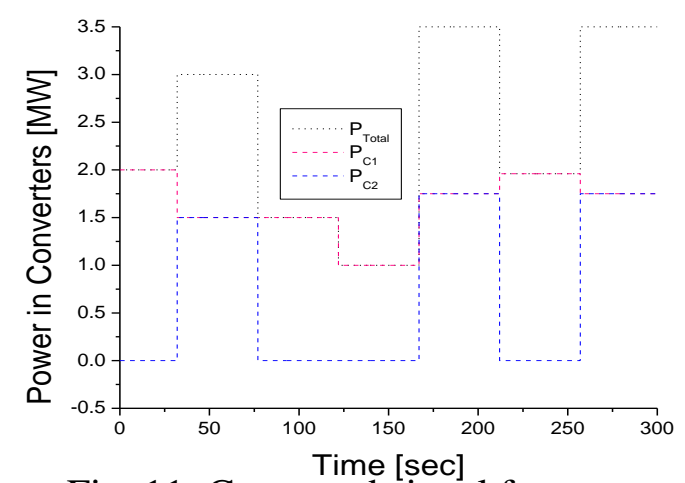

Fig. 11. Command signal for converters in CSU for local mode

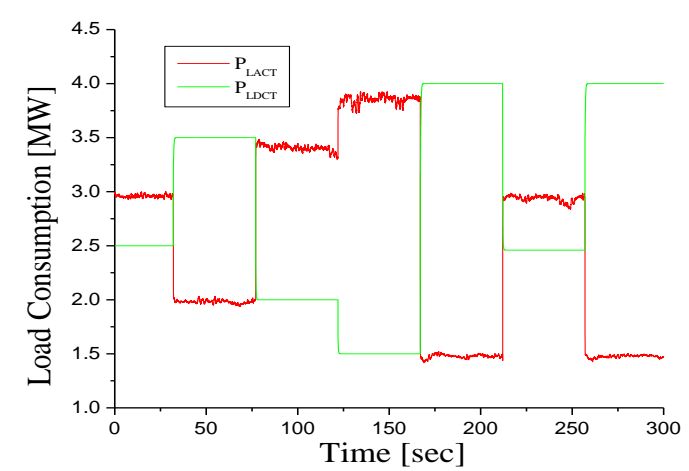

Fig. 13. Ac and dc loads for local mode

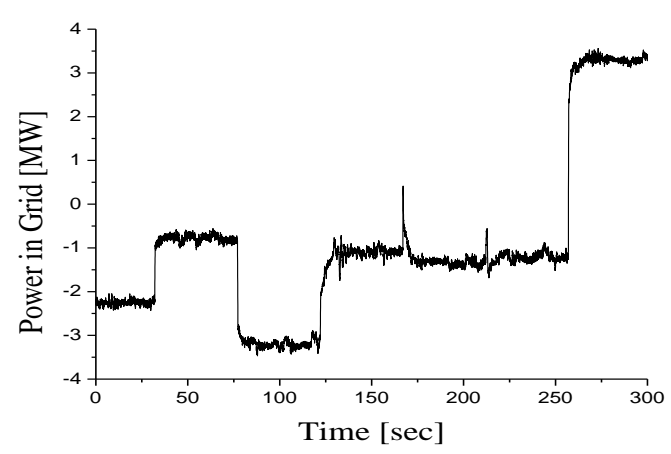

Fig. 15. Power flow control between grid and micro-grid for grid mode

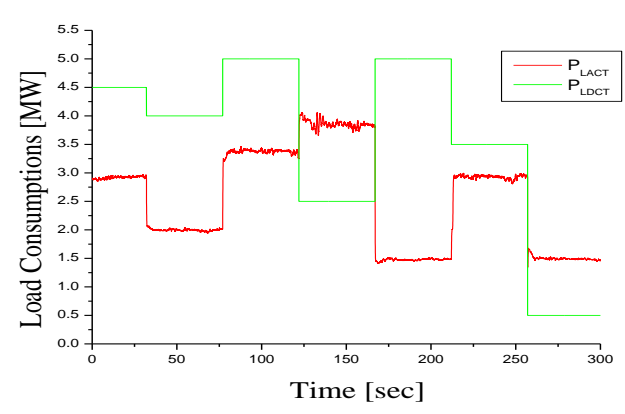

Fig. 17. Ac and dc loads for grid mode 


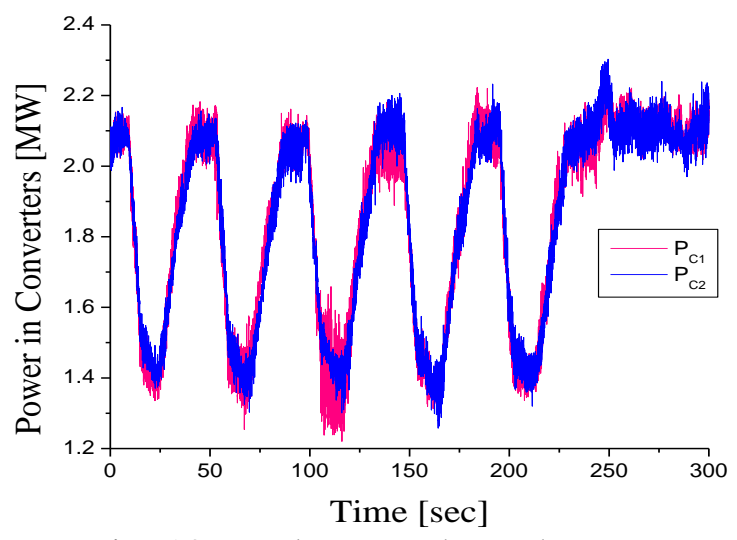

Fig. 18. Real power through power converters using real time ac load for local mode

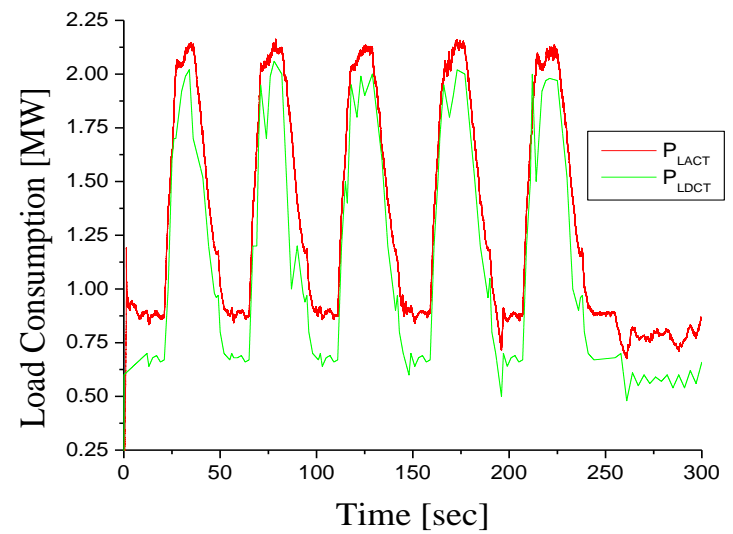

Fig. 20. Real time ac load and real time dc loads for grid mode

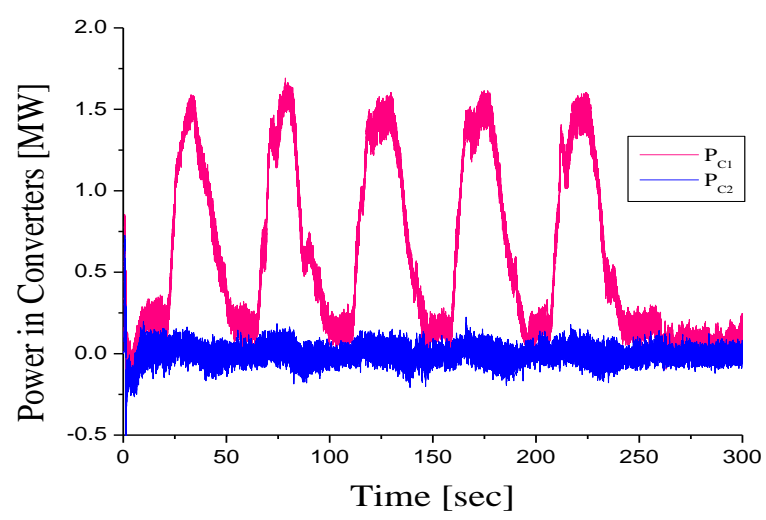

Fig. 22. Real power through power converters using real time ac and dc load for grid mode

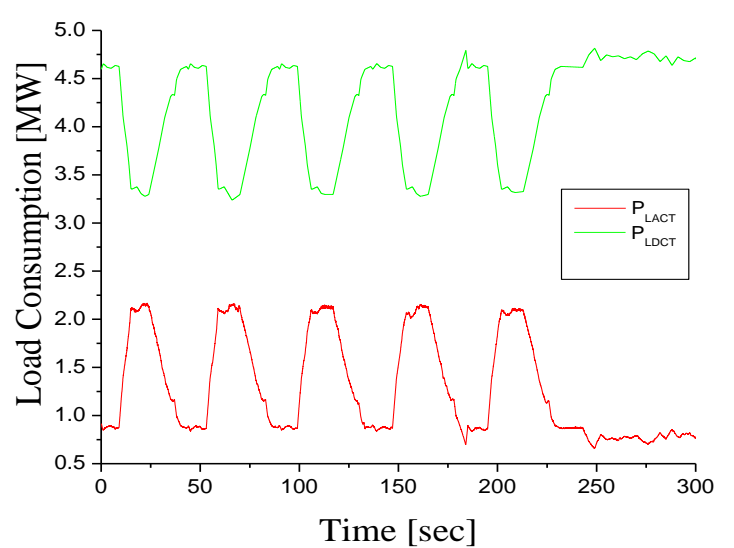

Fig. 19. Real time ac load and adjusted dc loads for local mode

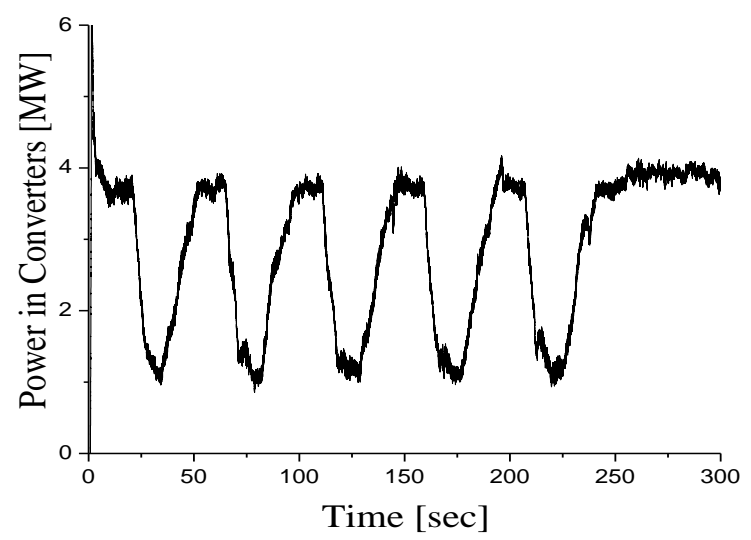

Fig. 21. Power flow control between grid and micro-grid for grid mode with real time ac and dc load 